\title{
A síndrome do esgotamento profissional (Burnout) como injúria aos direitos trabalhistas: princípios do dano existencial
}

\author{
Burnout syndrome as an injury to labor rights: principles of existential damage
}

Síndrome de burnout como lesión de los derechos laborales: principios de daño existencial

Tarcísio da Silva Flores ${ }^{1}$, Pablo Luiz Santos Couto ${ }^{2 *}$, Alba Benemérita Alves Vilela ${ }^{3}$, Jefferson de Almeida Silva ${ }^{4}$, Samantha Souza da Costa Pereira $^{5}$, Elvira Cavalcanti de Souza ${ }^{6}$

Como citar esse artigo. Flores, TS; Couto, PLS; Vilela, ABA; Silva, JA; Pereira, SSC; de Souza, EC. A síndrome do esgotamento profissional (Burnout) como injúria aos direitos trabalhistas: princípios do dano existencial. Revista Pró-UniverSUS. 2019 Jul./Dez.; 10 (2): $48-52$

\begin{abstract}
Resumo
Objetivou-se analisar reflexivamente acerca da injúria aos direitos fundamentais garantidos ao trabalhador brasileiro pela Constituição Federal, na questão ambiental e do dano existencial, com enfoque na relação com a síndrome de Burnout. Trata-se de um estudo teórico-reflexivo sobre o estado da arte das publicações levantadas e da Constituição Federal Brasileira, quanto ao dano existencial e seus aspectos jurídicos trabalhistas. É notório que o ambiente laboral, as relações humanas estabelecidas nele e o assédio moral cotidiano, tem se tornado um dos grandes inimigos contra o direito ao gozo do lazer, bem como a intimidade e a privacidade do trabalhador, configurando-se dano existencial e contribuindo para seu esgotamento mental e físico, o que caracteriza a síndrome de Burnout.
\end{abstract}

Palavras-chave: Saúde do Trabalhador, Direitos Trabalhistas, Síndrome de Burnout, Dano Existencial, Esgotamento Mental.

\begin{abstract}
The objective was to analyze reflexively about the injury to the fundamental rights guaranteed to the Brazilian worker by the Federal Constitution, the relation of the environmental issue and the existential damage, focusing on the relation with the Burnout syndrome. This is a theoretical-reflective study on the state of the art of the publications published and the Brazilian Federal Constitution, regarding the existential damage and its labor legal aspects. It is notorious that the work environment, the human relations established in it and the daily bullying, have become one of the great enemies against the right to enjoyment of leisure, as well as the privacy and privacy of the worker, constituting existential damage and contributing for their mental and physical exhaustion, which characterizes Burnout syndrome

Keywords: Worker's Health, Labor Rights; Burnout Syndrome, Existential Damage, Mental Exhaustion.
\end{abstract}

\section{Resumen}

El objetivo de este estudio fue analizar reflexivamente la lesión de los derechos fundamentales garantizados al trabajador brasileño por la Constitución Federal con respecto a la relación entre los problemas ambientales y los daños existenciales, centrándose en la relación con el síndrome de Burnout. Este es un estudio teórico-reflexivo sobre el estado del arte de las publicaciones publicadas y la Constitución Federal de Brasil, con respecto al daño existencial y sus aspectos legales laborales. Es notorio que el ambiente de trabajo, las relaciones humanas establecidas en él y la intimidación diaria, se han convertido en uno de los grandes enemigos contra el derecho al disfrute del ocio, así como la privacidad y privacidad del trabajador, lo que constituye un daño existencial y contribuye por su agotamiento mental y físico, que caracteriza el síndrome de Burnout.

Palabras clave: Salud Ocupacional, Derechos Laborales, Síndrome de Burnout, Daño Existencial, Agotamiento Mental.

Afiliação dos autores: 1. Advogado. Especialista em Direito e Processo do Trabalho. Centro de Ensino Superior de Guanambi. Guanambi, Bahia, Brasil.Email: tarcisiosflores@gmail. com ORCID: https://orcid.org/0000-0001-6350-2698

2. Enfermeiro Mestre em Enfermagem. Centro de Ensino Superior de Guanambi. Guanambi, Bahia, Brasil. Email: pablocouto0710@gmail.com ORCID: https://orcid.org/0000-00022692-9243

3. Enfermeira. Doutora em Enfermagem. Universidade Estadual do Sudoeste da Bahia. Jequié, Bahia, Brasil. Email: albavilela@gmail.com ORCID:https://orcid.org/0000-0002$1187-0437$

4. Advogado. Bacharel em Direito. Centro de Ensino Superior de Guanambi. Guanambi, Bahia, Brasil. Email: jalmeida@hotmail.com ORCID: https://orcid.org/0000-0003-20979693

5. Enfermeira. Mestra em Saúde Coletiva. Centro de Ensino Superior de Guanambi. Guanambi, Bahia, Brasil. Email: samantha.uefs@gmail.com ORCID:https://orcid.org/0000-0001 $-5978-520 \mathrm{X}$

6. Pedagoga. Especialita em Psicopedagogia e Mestra em Educação. Centro de Ensino Superior de Guanambi. Guanambi, Bahia, Brasil. Email: e.cavalcantisouza@gmail.com ORCID:https://orcid.org/0000-0001-6418-568X 


\section{Introdução}

Com a proclamação da República, e a devida promulgação da Consolidação das Leis do Trabalho (CLT), respectivamente, os direitos concernentes aos trabalhadores foram ganhando espaço na legislação brasileira, principalmente ao regulamentar as relações entre o empregado e patrão ${ }^{1}$. Mesmo que de forma lenta, e muitas das vezes tendo seus direitos prejudicados, os trabalhadores vêm alcançando suas garantias com o decorrer do tempo, graças aos variados estudos que buscam incansavelmente afastar a imagem de escravatura ainda muito real na seara trabalhista ${ }^{2}$.

Dentre vários direitos já assegurados, o direito ao lazer, assim como a intimidade e a privacidade, vem conquistando a atenção de muitos pesquisadores devido a preocupação com o desvio na qualidade de vida do trabalhador brasileiro ao se verem afetados socialmente e psicologicamente pelo trabalho excessivo com poucas horas de tempo livre ${ }^{3-4}$.

Contudo, o trabalhador brasileiro ainda enfrenta, em grande parte do país, dificuldades na valorização de sua qualidade como empregado, chamando atenção, muitasvezes, pelas peculiaridades em que é submetido no ambiente laboral ${ }^{5-6}$. Quando se pensa em qualidade de vida logo remete-se a um desafio diário,no qual o ser humano busca a valorização das condições contributivas para o seu bem estar físico e espiritual, principalmente se tratando sobre a saúde e segurança na seara trabalhista ${ }^{2-}$ 3,6 .

No ambiente de trabalho, profissionais de diversas áreas são submetidos a trabalhos cansativos, sobrecarregados, visando a aquisição de grandes taxas de produção, onde o principal interesse é produzir mais lucro ao empregador, sem se importar com a dignidade da pessoa humana, e lamentavelmente ao fim desencadeia no empregado os sintomas da Síndrome de Burnout ${ }^{7}$. Essa síndrome é conhecida como a síndrome do esgotamento profissional, sendo uma desordem psicossocial, em decorrênciado estresse emocional e de caráter depressivo, com relação direta à atividade desenvolvida no trabalho e os problemas nas relações humanas, assim como ao assédio moral desenvolvido no ambiente laboral por parte dos líderes ${ }^{6,8}$.

Sabe-se que a Constituição Federal protege o direito à privacidade, sendo esta relacionada a intimidade, a honra e a imagem e o dano existencial causa injúria a tais direitos. A intimidade é tratada como o modo de ser do indivíduo, a parte espiritual em conjunto com os sentimentos, autoestima, autoconfiança, marcado pela confidência aos demais, trata-se do modo de ser, a identidade da pessoa. Já a vida privada é avaliada em um rol mais amplo, carregada de informações na qual apenas o indivíduo tem o direito de decidir sobre sua divulgação? .
Assim, a intimidade é aquela que traduz a parte íntima da pessoa, seus sentimentos mais afeiçoados. Já o dano existencial afronta diretamente a rotina da pessoa, altera seu cotidiano de forma que lhe cause desgosto pelo convívio social e consequentemente alterando sua qualidade de vida ${ }^{10}$.

O dano existencial, que também pode ser reconhecido como o dano à existência do trabalhador, possui sua defesa no sentido que todo ser humano precisa possuir um sentindo à sua existência no mundo, um lugar em meio à sociedade onde seja possível manifestar suas habilidades, porém é vandalizado quando uma conduta patronal o impede de manter relações e convivências junto à sociedade por meio de atividades de descanso que proporcionem bem estar tanto físico como psíquico $^{9-}$ 11 .

Reconhecer os fatores que geram essa síndrome é de grande importância para alcançar mecanismos que previnem o desenvolvimento e a descoberta tardia dos sintomas que prejudicam diretamente a saúde do trabalhador e as condições dignas de sobrevivência do ser humano.

Dessa forma, estudo versasobre o estresse ocupacional no ambiente de trabalho, quando o trabalhador não mais consegue se desenvolver nas demandas do seu serviço, causando-lhe dor psíquica com sérios resquícios em sua qualificação como profissional. Ainda, em sequência, adentra-se em questão jurídicofilosófico, fazendo-se necessário analisar reflexivamente acerca dainjúria aos direitos fundamentais garantidos ao trabalhador brasileiro pela Constituição Federal; o direito à saúde, ao trabalho, e ao ambiente de trabalho saudável, sendo necessário que se avalie minuciosamente a relação da questão ambientale do dano existencial, com enfoque ao meio ambiente do trabalho digno com roupagem de direito fundamentalíssimo.

\section{Metodologia}

Trata-se de estudo reflexivo-teórico sobre o estado da arte das publicações levantadas e da Constituição Federal Brasileira, quantoao dano existencial e seus aspectos jurídicos,na esfera da legislação trabalhistas. A busca pela literatura ocorreu no ano de 2018, no período de junho e julho com os descritores "Direitos trabalhistas" e "Síndrome de Burnout" associados às palavras chaves "Dano existencial" e "Esgotamento mental", com a utilização do operador boleano "and", nas bases de dados: Biblioteca Virtual em Saúde (BVS), Medical Literature Analysis and Retrieval System Online (MEDLINE) e Scientific Eletronic Library Online (SCIELO). Não foi estabelecido recorte temporal, tendo em vista os poucos estudos desenvolvidos tanto na área jurídica quanto da saúde, envolvendo o delineamento do objeto apresentado nesse presente estudo. 


\section{Dano existencial nas relações trabalhistas e a síndrome de Burnout}

Ao se tratar sobre o dano existencial inerente ao direito trabalhista, é preciso compreender que todo seu conceito é pautado no princípio da proteção ao empregado, que tem como função aplicar as principais dessemelhanças financeiras envolvendo o empregador e seu subordinado, obviamente com um acolhimento jurídico voltado preferencialmente ao empregado que veste a farda de hipossuficiente na relação ${ }^{12}$.

Este princípio da proteção ao trabalhador encontra-se dividido em duas modalidades. A primeira, a "in dubio pro operário" de forma moderna, tem como finalidade proteger a parte menos favorecida no litígio, no caso o empregado, esta modalidade se sustenta quando há dúvida em relação à interpretação ou aplicação de determinada norma jurídica, devendo ser aplicada aquela que melhor favorecer o trabalhador desde que não afronte diretamente a vontade do legislador ${ }^{13}$. Ressaltase que in dubio pro operário é também reconhecido por alguns doutrinadores como "in dubio pro mísero", onde havendo apenas uma regra aplicável, esta possua mais de uma interpretação, devendo ser adotada aquela que for mais vantajosa ao empregado ${ }^{13}$.

A segunda modalidade, parte do princípio de proteção ao trabalhador e que busca olhar sobre o dano existencial, está voltada a "aplicação da condição mais benéfica ao trabalhador", neste caso quando o empregado alcança determinadas vantagens, estas não poderão ser modificadas com o intuito de prejudicá-lo ${ }^{13}$.

A teoria do dano existencial está sendo favoravelmente reconhecida pela jurisprudência e doutrina brasileira tendo como exemplo o Direito Italiano que originou os estudos sobre o tema ${ }^{14}$. De fato, o dispositivo que reconhece o dano existencial está bem recente no ordenamento, tendo sido acolhido com o advento da Lei 13.467/2017 que alterou a Consolidação das Leis do Trabalho (CLT). Porém, anteriormente a esta Lei, a fundamentação era feita com previsões retiradas da própria Constituição Federal por fundamentos do Estado Democrático de Direito, da defesa à dignidade da pessoa humana, do direito à liberdade, princípio da solidariedade, a vida privada, o direito ao lazer, todos em busca de um bem-estar digno ao ser humano ${ }^{13-14}$.

Este instituto, infelizmente, ainda não é costumeiramente utilizado pelos operadores do direito, mas tem sido objeto de defesa de alguns doutrinadores que tutelam a possibilidade e o dever da justiça em acolher este dano existencial ${ }^{1,15}$. Mas com a Reforma da CLT, e com a incansável luta pela doutrina, cada vez mais os tribunais estão acatando essa teoria no direito do trabalho brasileiro e concedendo a indenização aos trabalhadores pela frustação em seus projetos de vida, e moléstia à relação entre as pessoas ${ }^{9,11}$.
A teoria do dano existencial está sendo favoravelmente reconhecida pela jurisprudência e doutrina brasileira tendo como exemplo o Direito Italiano que originou os estudos sobre o tema. De fato, o dispositivo que reconhece o dano existencial está bem recente no ordenamento, tendo sido acolhido com o advento da Lei 13.467/2017 que alterou a Consolidação das Leis do Trabalho(CLT) ${ }^{12}$. Porém, anteriormente a esta Lei, a fundamentação era feita com previsões retiradas da própria Constituição Federal por fundamentos do Estado Democrático de Direito, da defesa à dignidade da pessoa humana, do direito à liberdade, princípio da solidariedade, a vida privada, o direito ao lazer, todos em busca de um bem-estar digno ao ser humano ${ }^{13}$.

Este instituto, infelizmente, ainda não é costumeiramente utilizado pelos operadores do direito, mas tem sido objeto de defesa de alguns doutrinadores que tutelam a possibilidade e o dever da justiça em acolher este dano existencia ${ }^{10}$. Mas com a Reforma da CLT, e com a incansável luta pela doutrina, cada vez mais os tribunais estão acatando essa teoria no direito do trabalho brasileiro e concedendo a indenização aos trabalhadores pela frustação em seus projetos de vida, e moléstia à relação entre as pessoas ${ }^{2}$.

A incidência do dano existencial na seara trabalhista é possível por inúmeras formas, as mais conhecidas delas são: a jornada excessiva de trabalho, onde o trabalhador é submetido a uma jornada que extrapole os limites permitidos pela legislação, ainda que as horas extras sejam pagas; a não autorização para que o empregado tire suas merecidas férias anual; quando o trabalhador é acometido por alguma doença decorrente de seu serviço, entre vários mais ${ }^{13-14}$. Todas essas hipóteses mencionadas são exemplos em que a relação interpessoal e o projeto de vida do trabalhador são afetados drasticamente ${ }^{9}$.

Porém, ressalta-se que o dano existencial que provem das relações de trabalho, não necessariamente se remete apenas às ações resultantes do poder do patrão sob o empregado, existem outros fatores que influenciarão diretamente na incidência desse dano, como o assédio, humilhação pelos próprios colegas de trabalho, que de fato serão os autores do ato ilícito que ensejará no desenvolvimento do dano existencial na vida do empregado ${ }^{5-6,11}$.

A principal característica nesta espécie de dano é notória quando o indivíduo prejudicado, encontra-se privado de exercer os direitos fundamentais que lhe são garantidos pela Constituição Federal, principalmente de usufruir o seu tempo da forma que melhor lhe convém, sendo assediado moralmente pelo empregador ${ }^{15}$ :nas relações de trabalho o dano existencial decorre da conduta patronal que impossibilita o empregado de se relacionar e de conviver em sociedade por meio de atividades recreativas, afetivas, espirituais, culturais, sociais e de descanso, que lhe trarão bem-estar físico 
e psíquico e, por consequência, felicidade; ou que o impede de executar, de prosseguir ou mesmo de recompor os seus projetos de vida, que serão, por sua vez, responsáveis pelo seu crescimento ou realização profissional, social e pessoal ${ }^{15: 44}$.

Qualquer ser humano é possuidor do direito de não ser lesado por terceiros, seja qual for a modalidade de afronta, podendo ser física, mental, social, entre outras mais. Pode-se dizer que é da natureza do indivíduo necessitar de um descanso ao final de cada expediente trabalhado, naturalmente, sempre buscará uma maneira para se restaurar, sendo que, é direito do trabalhador recompor suas forças antes de retornar às atividades casualmente desenvolvidas, sob pena de estar sendo acometido pela fadiga e ao fim se enquadrar no dano existencial resultante do esforço laboral excessivo ${ }^{3-4,11}$

A doutrina atual ainda não possui um posicionamento unificado sobre a viabilidade de aplicar o dano existencial através de apenas um ato do patrão. O raciocínio que vigora atualmente é que para se configurar o dano existencial será necessária uma conduta ilícita que viole o projeto de vida do indivíduo, ou afronte sua vida de relações com terceiros, assim como, esta ação perpetrada pelo empregador deverá ser realizada repetidamente, ou seja, entende-se que o incidente realizado em conduta única não ferirá os direitos básicos do trabalhador de forma expressiva $a^{2,6,10}$.

Inicialmente é preciso mencionar que a saúde do funcionário é tratada especialmente como um bem fundamental garantido pela Constituição Federal, possuindo grande importância no comportamento e exercício do trabalhador, de forma que, a empresa que não respeite ou negligencie esse direito acarreta uma enorme consequência negativa para o desenvolvimento da empresa e saúde do próprio funcionário, acarretando em desordens físicas e emocionais/mentais ${ }^{14,16}$.

A expressão "Burnout", originária da língua inglesa, foi utilizada inicialmente a partir de 1969 através de estudos que tratavam de doenças que surgiam nos trabalhadores mas erroneamente de forma taxativa apenas aos profissionais da área de saúde e policiais. Não obstante, sabe-se que essa síndrome pode estar presente na vida de todo trabalhador e em qualquer área profissional $^{17}$.

Assim como os sintomas apresentados acima, o indivíduo portador da síndrome de Burnout pode demonstrar outras atitudes com o intuito de se defender, como se isolar, se tornar uma pessoa irônica com os demais, e também perder o interesse pelo lazer, que consequentemente o deixará propenso a se enquadrar em um dano existencial. Essa síndrome decorre do dano existencial, por ferir a liberdade do trabalhador e minar suas possibilidades de intimidade e privacidade fora do ambiente laboral ${ }^{7}$.
A síndrome de Burnout para fins previdenciários é classificada com CID10 (Z73.0), e de acordo a doutrina atual o auxílio é devido às pessoas quando apresentam principalmente a exaustão emocional decorrente do trabalho, assim como outros quesitos como o processo psíquico da despersonalização e a pouca realização profissional na atuação do trabalho ${ }^{5,16}$.

A exaustão emocional pode ser reconhecida como um sentimento resistente que promove descontrole nas emoções do indivíduo, acarretando em esgotamento e perda de energia ao enfrentar a prática do serviço costumeiramente realizada. A despersonalização, por sua vez, é a consequência ao desenvolver um comportamento desprovido de positividade em total contradição à personalidade rotineira do indivíduo no ambiente de trabalho ${ }^{7,17}$.

Por conseguinte, a ausência de realização profissional é aquela que abala as atitudes do trabalhador envolvendo a prática da profissão, influenciando diretamente no relacionamento com terceiros ou no sistema organizacional da empresa, de forma que ao final ele se avalie negativamente ${ }^{6}$. Sendo assim, o trabalhador se sente altamente infeliz e irrealizado com suas atividades profissionais, de maneira que as coisas perdem a devida importância, e toda dedicação empregada no trabalho se torna ineficaz, tudo como consequência do assédio moral cotidiano no ambiente laboral, da privacidade e da intimidade fora do trabalho afetadas e consequentemente, o dano existencial ${ }^{13}$.

A exaustão emocional pode ser reconhecida como um sentimento resistente que promove descontrole nas emoções do indivíduo, acarretando em esgotamento e perda de energia ao enfrentar a prática do serviço costumeiramente realizada. A despersonalização, por sua vez, é a consequência ao desenvolver um comportamento desprovido de positividade em total contradição à personalidade rotineira do indivíduo no ambiente de trabalho ${ }^{1}$. Por derradeiro, a ausência de realização profissional é aquela que abala as atitudes do trabalhador envolvendo a prática da profissão, influenciando diretamente no relacionamento com terceiros ou no sistema organizacional da empresa, de forma que ao final ele se avalie negativamente ${ }^{8}$. Sendo assim, o trabalhador se sente altamente infeliz e irrealizado com suas atividades profissionais, de maneira que as coisas perdem a devida importância, e toda dedicação empregada no trabalho se torna ineficaz ${ }^{4-5}$.

Na jurisprudência atual do Brasil, já é possível encontrar alguns julgados condenando a reclamada em indenização por danos morais por submeter seus funcionários a situações que afete o seu bem estar mental e físico, decorrentes de assédio moral e promovendo o dano existencial. Assim entendeu o Tribunal Superior do Trabalho ao manter uma indenização que condenava a Demandada em R\$ 100.000,00 (cem mil reais), por desenvolver a síndrome de Burnout no trabalhador ${ }^{18}$. 
Percebe-se uma grande semelhança entre a síndrome de Burnout e o dano existencial, abordado anteriormente, na qual, a principal preocupação é focada primordialmente na saúde do trabalhador, tanto mental quanto física. Porém, cabe salientar que a síndrome do esgotamento profissional se diferencia das demais formas de estresse na medida em que esta se relaciona diretamente à rotina do trabalho.

\section{Conclusão}

Notou-se que a dignidade da pessoa humana são temas multifacetados no Direito, seus diferentes conceitos e ramos se encontram harmonicamente quando trata-se sobre o bem estar e qualidade de vida do trabalhador brasileiro, abarcando principalmente seus campos sociais, culturais, dentre outros mais, concluindo-se sempre pelo zelo ao mínimo existencial em prol de uma vida digna à todos os indivíduos.

É notório que o ambiente laboral, as relações humanas estabelecidas nele e o assédio moral cotidiano, tem se tornado um dos grandes inimigos contra o direito ao gozo do lazer, bem como a intimidade e a privacidade na medida em que os empregadores exploram de uma jornada de trabalho exaustiva e lesiva ao trabalhador, com o intuito unicamente de proveitos econômicos, resultando no impedimento do empregado de desfrutar do ócio e de seu desenvolvimento social.

Para tal, conclui-se que é precioso compreender que o direito ao lazer, a intimidade e a privacidade é um direito social necessário, garantido pela Constituição Federal e fundamental para se exercer a cidadania, assim como, e não menos importante, assimilar a sua função em consonância com o princípio da dignidade da pessoa humana, e ao fim condenar os autocratas e indenizar as vítimas, pois somente assim pode-se finalmente reconhecer que este direito ao descanso é componente fundamentalíssimo para o bem estar do trabalhador brasileiro e para a prevenção da síndrome do esgotamento físico e mental, a síndrome de Burnout.

\section{Referências}

1. Mossi TW. Lutas trabalhistas como lutas minoritárias: a questão da dignidade do trabalhador terceirizado. Sociologias. 2019 Jan./Abr.; 21(50):236-59.

2. Bonfim VC. Direito do trabalho. 11 $1^{\mathrm{a}}$. Edição. Rio de Janeiro: Forense, 2015

3. Lunardi A. Função social do direito ao lazer nas relações de trabalho. São Paulo: LTr, 2010.

4. Dumazedier J. Sociologia empírica do lazer. São Paulo: Perspectiva SESC, 1979.

5. Benevides-Pereira AMT. Burnout: quando o trabalho ameaça o bem-estar do trabalhador. São Paulo: Casa do Psicólogo; 2002.

6. Neves VF, Oliveira AF, Alves PC. Síndrome de Burnout: Impacto da satisfação no trabalho e da percepção de suporte organizacional. Psico. 2014;45(1):45-54.

7. Merces MC, Gomes AMT, Guimarães ELP, Santana AIC, Silva DS, Machado YY et al. Burnout y condiciones metabólicas en profesionales de enfermería: un estudio piloto. EnfermagemBrasil. 2018;17(2):90-8.

8. Couto PLS, Oliveira SCCGSS de, Paes LB. Power relations in hospital emergency: the look of the nursing team. J Nurs UFPE online. 2014 Oct;8(Suppl. 2):3607-15.

9. Krohling A. A ética da alteridade e da responsabilidade. Curitiba: Juruá, 2011

10. Boucinhas Filho JC. O dano existencial e o direito do trabalho. Revista Magister de Direito do Trabalho. 2013 Nov./Dez.; 10(57).

11. Guedes MN. Terror psicológico no trabalho. $3^{\text {a }}$. Edição. São Paulo: LTr, 2008.

12. Frota HA. Noções fundamentais sobre o dano existencial. JusLaboris Revista Eletrônica. 2013 Set.;1(1):62-78.

13. Soares FR. Responsabilidade civil por dano existencial. Porto Alegre: Livraria do Advogado, 2009.

14. Boucinhas Filho JC, Alvarenga RZ. O dano existencial e o Direito do Trabalho. Revista eletrônica do Tribunal Regional do Paraná. 2013;2(22):2651

15. Boucinhas Filho JC. Aplicação da teoria da responsabilidade civil por perda de uma chance às relações de trabalho. Revista Justiça do Trabalho. 2010 Jun.;27(318)

16. Canova KR, Porto JB. O impacto dos valores organizacionais no estresse ocupacional: um estudo com professores de ensino médio. RevAdmin Mackenzie. 2010;11(5):4-31.

17. Coser A. Síndrome de Burnout: a doença laboral da contemporaneidade e a questão da responsabilidade civil. FADERGS. 2013;5(2):43-73.

18. Brasil. Tribunal Superior do Trabalho. AIRR: 22568120145120060, Relator: Antonio José de Barros Levenhagen, Data de Julgamento: 08/02/2017, $5^{\text {a }}$ Turma. Jus Brasil, 2017. Disponível em: $<$ https://tst.jusbrasil. com.br/jurisprudencia/429114726/agravo-de-instrumento-em-recurso-derevista-airr-22568120145120060/inteiro-teor-429114758> Acesso em: 22 de abril de 2018. 